\title{
Evaluating the mutagenic potential of aerosol organic compounds using informatics-based screening
}

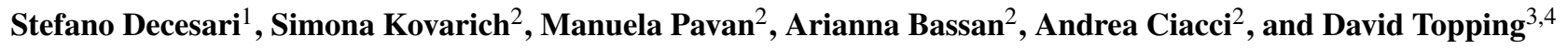 \\ ${ }^{1}$ Institute of Atmospheric Sciences and Climate, National Research Council of Italy (ISAC-CNR), 40121, Bologna, Italy \\ ${ }^{2}$ S-IN Soluzioni Informatiche Srl, 36100, Vicenza, Italy \\ ${ }^{3}$ School of Earth, Atmospheric and Environmental Sciences, The University of Manchester, M13 9PL, UK \\ ${ }^{4}$ National Centre for Atmospheric Science, The University of Manchester, M13 9PL, UK
}

Correspondence: Stefano Decesari (s.decesari@isac.cnr.it)

Received: 20 June 2017 - Discussion started: 17 July 2017

Revised: 27 October 2017 - Accepted: 29 December 2017 - Published: 16 February 2018

\begin{abstract}
Whilst general policy objectives to reduce airborne particulate matter (PM) health effects are to reduce exposure to PM as a whole, emerging evidence suggests that more detailed metrics associating impacts with different aerosol components might be needed. Since it is impossible to conduct toxicological screening on all possible molecular species expected to occur in aerosol, in this study we perform a proof-of-concept evaluation on the information retrieved from in silico toxicological predictions, in which a subset $(N=104)$ of secondary organic aerosol (SOA) compounds were screened for their mutagenicity potential. An extensive database search showed that experimental data are available for $13 \%$ of the compounds, while reliable predictions were obtained for $82 \%$. A multivariate statistical analysis of the compounds based on their physico-chemical, structural, and mechanistic properties showed that $80 \%$ of the compounds predicted as mutagenic were grouped into six clusters, three of which (five-membered lactones from monoterpene oxidation, oxygenated multifunctional compounds from substituted benzene oxidation, and hydroperoxides from several precursors) represent new candidate groups of compounds for future toxicological screenings. These results demonstrate that coupling model-generated compositions to in silico toxicological screening might enable more comprehensive exploration of the mutagenic potential of specific SOA components.
\end{abstract}

\section{Introduction}

Ambient air pollution was ranked as the seventh highest risk factor for human health (Lim et al., 2012), being responsible for almost 3 billion deaths per year globally. Evidence for air pollution impacts on life expectancy and for cardiovascular and respiratory illnesses has grown considerably in the last 2 decades (Beelen et al., 2014), and the ongoing global demographic and societal changes (ageing, urbanization) are projected to exacerbate atmospheric pollution health effects. Evidence from both short- and long-term epidemiological effects of particulate matter with particle diameters below 10 or $2.5 \mu \mathrm{m}\left(\mathrm{PM}_{10}\right.$ or $\mathrm{PM}_{2.5}$, respectively) is robust, with a range of possible policies aiming to mitigate PM health effects reflected by the possible sources from which PM arises.

Since at least the early 2000s, metrics for PM chemical composition and sources have been incorporated along with $\mathrm{PM}_{10}, \mathrm{PM}_{2.5}$, or $\mathrm{PM}_{0.1}$ (ultrafine) in epidemiological studies. Recently, black carbon (BC), which is a proxy for primary combustion particles, was associated with an increased risk of mortality 2 times greater than for total PM (Janssen et al., 2011). Recent findings highlight the fact that more detailed air quality metrics may be valuable in evaluating health risks by specifically distinguishing between, for example, black carbon, secondary organic aerosols, and inorganic aerosols (Cassee et al., 2013). A study in London, UK suggested that certain particle components might be more important to specific diseases (Atkinson et al., 2010), with some toxicological studies suggesting pulmonary and vascular inflammation as the relevant biological response mechanism (WHO, 2013; HEI, 2010). Despite this, the overarching developments of 
policy objectives remain to substantially reduce population exposure to $\mathrm{PM}_{2.5}$ as a whole. Stanek et al. (2011) provided a compilation and meta-analysis of 29 epidemiological and in vivo toxicological studies that explicitly investigated the statistical relationship between PM chemical composition and adverse health effects. They noted that, from a mechanistic perspective, it is highly plausible that the chemical composition of particulate matter (PM) would better predict health effects than other characteristics, such as PM mass or size (Stanek et al., 2011). However, their conclusion is that no consistent relationships have emerged so far: there is little evidence of a systematic association of specific groups of compounds with adverse effects across all studies. Possible reasons for the inconsistencies among epidemiological results are the paucity of studies, non-additive (synergic) effects of pollutants, and study design issues such as differences in the exposed populations, differences in pollution levels between environments, and differences in the air quality networks. In particular, the sets of PM chemical compounds measured by different monitoring networks overlap for only a few species: metals, inorganic ions, $\mathrm{BC}$, and possibly organic carbon (OC), with little or no information on OC molecular composition. West et al. (2016) note that epidemiologic studies should consider other air pollutants suspected to be important for health, such as polycyclic aromatic hydrocarbons (PAHs), metals, reactive oxygen species (ROS), and other chemical components of PM. These include classes of compounds defined by their reactivity (ROS) with unclear overlaps with the other compounds in the list (Zhang et al., 2008). More importantly, guidelines should be provided for the identification of possible targets (the compounds suspected to be important for health). A group of commonly monitored substances (PAHs and metals) has been extensively characterized by the toxicological research on combustion and industrial aerosols. On the other hand, the recent advances in the chemical characterization of ambient organic particles, including secondary organic aerosol (SOA; Hallquist et al., 2009), have been exploited in PM toxicology only to a limited extent (Verma et al., 2015; Lakey et al., 2016). Given that emerging evidence points towards the need for more information on associations between health impact potential and separate PM fractions, it is worthwhile to evaluate the role of emerging technologies in extracting this information.

At present, only information on bulk SOA in vivo and in vitro biological effects is available (Delfino et al., 2008; Chen et al., 2011; Rohr et al., 2013; Saffari et al., 2015; Künzi et al., 2015). The lack of actual molecular targets for the SOA fraction responsible for its toxicity might pose limitations to the design of epidemiological studies incorporating specific SOA tracers. Moreover, while molecular identification of SOA compounds is normally achieved through the analysis of exact molecular masses and the interpretation of mass fragmentation spectra, the synthesis of authentic standards has been conducted to a very limited extent and for few com- pounds. The lack of standards is critical for the determination of toxicity endpoints via classical toxicological assays. Estimation of such endpoints can be pursued, however, on the basis of the sole chemical composition by means of in silico approaches, such as quantitative structure-activity relationships (QSARs). In silico toxicology is widely used in drug chemistry, especially as a screening before in vitro and in vivo assays. In particular, QSARs are theoretical models relying on a mathematical relationship (often a statistical correlation) between one or more quantitative parameters derived from chemical structure and a quantitative measure of a property or activity (e.g. a toxicological endpoint). The reliability of a QSAR prediction highly depends on the scientific validity of the employed QSAR model, which should fulfil the internationally recognized principles for QSAR validation as defined by the OECD (OECD, 2004, 2006, 2007), and the applicability domain of the QSAR model, i.e. whether the compound of interest is sufficiently similar to the compounds used to train the model (Netzeva et al., 2005; Sushko et al., 2010; Sahigara et al., 2012). So far, as noted previously, the use of in silico methods for the toxicological assessment of aerosol organic compounds has been limited and restricted to specific chemical classes like PAHs (Papa et al., 2008; Schwarz et al., 2014). In this study, we perform a proof-ofconcept evaluation on the information retrieved from in silico methods specifically applied to a subset of measured compounds attributed to multiple sources of SOA. These compounds have been largely unexplored with regards to their toxicological properties, and the general evaluation of available in silico methods has hitherto not been carried out. The potential of such methods is considerable as, in principle, toxicity endpoints of aerosols can be generated directly from molecular compositions that can either be measured directly or predicted using state-of-the-art explicit chemistry models.

This evaluation is timely. In the past decade, the rapid development of aerosol mass spectrometric techniques of increasing resolution has boosted the molecular identification of SOA compounds (Laskin et al., 2012; Nozière et al., 2015). At the same time, mechanistic models predict the chemical composition of SOA with an increasing degree of sophistication by accounting for the movement of compounds between the gaseous and condensed phases at a molecular level. Despite uncertainties in fundamental parameters leading to variable mass and composition predictions (McVay et al., 2016), the amount of information available from both measurement and modelling technologies might be combined to start associating health impact potential with distinct groups of compounds. This is the driver for the study presented here.

\section{Methods}

A list of $\sim 100$ SOA compounds was identified for subsequent toxicity predictions using in silico (i.e. QSAR) meth- 
ods. First, the in vitro genotoxicity data as bacterial mutagenicity (Ames test) available for these compounds were searched for in several international databases. Following this, QSAR predictions for bacterial mutagenicity were performed for all the species, and the results were compared to the toxicity endpoints determined by in vitro methods (for the subset of compounds for which in vitro data could be found). Finally, the results of the toxicity predictions were interpreted using a cluster analysis of the compounds based on a suite of molecular descriptors, including structural and mechanistic (in relation to express toxicity on humans), for understanding inter- and intra-class variability.

\subsection{Organic compounds}

A set of 104 compounds speciated according to biogenic and anthropogenic SOA was compiled for this proof-ofconcept study (Table S1 in the Supplement). They are organized into chemical classes defined as products originating from specific volatile organic compounds (VOCs). In order to keep the total number of compounds to $\sim 100$, a number of isomeric species have been filtered out. The list as a whole is an attempt to sample the greatly diverse chemical space of SOA species that can be derived from the vast literature on this subject. To create this list, exemplar molecular species were chosen to represent all relevant classes of SOA treated in recent review studies (Hallsquit et al., 2009; Nozière et al., 2015), which include the products of the oxidation of isoprene, monoterpenes $(\alpha-$ pinene, $\beta$-pinene, $\Delta 3$-carene, $d$-limonene), sesquiterpenes, and anthropogenic VOCs (substituted benzenes, alkenes, and amines). SOA compounds from intermediate-volatility organic precursors (IVOCs: low-molecular-weight PAHs and $\mathrm{C}_{12}-\mathrm{C}_{16} n$-alkanes) and examples of the products of heterogeneous (particle-phase) reactions of small carbonyls (glyoxal, methyl-glyoxal, pyruvic acid) are also included. Finally, highly reactive compounds forming from radical chemistry, such as secondary ozonides, adducts of carbonyls on Criegee intermediates (CIs), and polyperoxides (highly oxygenated organic molecules, HOMs), are accounted for. A range of secondary organic compounds missing an unequivocal source assignment, such as oxalic or succinic acid, were excluded.

The list in Table S1 includes compounds of varying degrees of identification factor (I factor; Nozière et al., 2015): for only a fraction of them a chromatographic separation, confirmation with standards, and quantification in real samples could be achieved. These include, for instance, the most common $\alpha$-pinene SOA tracers, including pinonic, hydroxyl-pinonic and pinic acids (mtr_05, mtr_06 and mtr_07 in Table S1), and terpenyllic, terebic, and diaterpenyllic acids (mtr_11, mtr_12 and mtr_13), 3-methyl1,2,3-butanetricarboxylic (MBTCA; mtr_17), together with their dimers (mtr_15, mtr_16), which can add up 10 to $15 \%$ of SOA mass (Kristensen et al., 2014). Other well-known
SOA compounds included in the list account for the isoprene chemistry: methyl-tetrols (iso_01 in Table S1), C5-alkene triols (iso_04), and their sulfate esters (iso_02) are common constituents of organic aerosols in rural areas, where they can account for $12-14 \%$ of ambient particulate organic matter (Lin et al., 2013). Concentration data for anthropogenic compounds, such as quinones and oxo- and nitro-PAHs, are also available in the literature (Chung et al., 2006; Huang et al., 2014). For most of the other organic compounds in the list, concentration data are simply not available. These include molecular species of uncertain identification and those with molecular structures that were inferred solely from the interpretation of mass spectra. It should be emphasized that this compound list was similarly formulated in order to maximize the diversity among molecular structures. As a consequence, the chemical classes that correspond to the most extensively studied laboratory SOA systems have more representative compounds than the SOA systems for which only a limited sets of conditions (e.g. photochemical) have been explored. Overall, the list of compounds was not designed to reproduce the entire molecular composition of SOA in any particular environment. In this sense, and to reiterate the rationale behind this study, we use this list of compounds to demonstrate the information that can be extracted from an in silico assessment of the mutagenic activity of the main classes of anthropogenic and biogenic atmospheric SOA. The computational workflow set up for this proof of concept can be further extended to even more chemical classes and toxicological endpoints.

\subsection{Toxicity endpoints}

Standard in silico methods employed in pharmaceutics and in chemical risk assessment enable the prediction of a variety of toxicological and eco-toxicological endpoints, such as skin and eye irritation, acute toxicity, genotoxicity, reproductive toxicity, and aquatic toxicity (Worth et al., 2011; Benfenati et al., 2016; ECHA, 2016). The present study focuses only on genotoxicity because (a) it can be associated with any kind of exposure, (b) it can be induced at very small doses, (c) it leads to adverse health effects on humans upon chronic exposure (and the increase in mortality risk for PM is much higher for chronic than for short-term exposures; Pope et al., 2011), and (d) it is a well-studied endpoint with defined mechanisms of action (Worth et al., 2011; Schultz et al., 2015). Most importantly, genotoxicity has been characterized in real PM samples and it is subject to monitoring in several countries (e.g. Cassoni et al., 2004). Past studies have attempted to apportion total PM mutagenicity among distinct primary organic aerosol sources (Hannigan et al., 2005). No such exercise has been carried out yet for SOA sources in spite of the fact the mutagenicity of SOA was demonstrated at least 30 years ago (Kamens et al., 1984). It is worth mentioning that mutagenicity is only one of the possible toxicological endpoints for atmospheric particulate organic com- 
pounds and that the same classes of compounds can be more or less toxic depending on the specific endpoints (e.g. mutagenicity vs. cytotoxicity, etc.; Filep et al., 2015).

In this study, QSAR predictions focus on Salmonella in vitro mutagenicity (Ames test). It should be noted that screening tests performed on strains of prokaryotes, such as the Ames test, are not meant to mimic exposure conditions for humans. They are used instead in the preliminary phases of hazard assessment, especially for hazard identification.

\subsection{Collection of experimental in vitro genotoxicity data}

In this study, a search for in vitro mutagenicity (Ames test) data available for the 104 aerosol compounds was performed with the support of the OECD QSAR Toolbox (OECD, 2009, 2013, 2015; a detailed description of the tool is provided in Supplement, Table S2). The toolbox is connected to a variety of toxicity databases and allows for the gathering of experimental data for the target compounds. The following databases were enquired for in vitro mutagenicity (Ames test) data: bacterial mutagenicity ISSSTY (by Istituto Superiore di Sanità), which includes TOXNET databases, the Carcinogenic Potency Database (CPDB), ECHA CHEM, Toxicity Japan MHLW (EXCHEM), Genotoxicity OASIS, and Carcinogenicity \& Mutagenicity ISSCAN. A brief explanation of the screened databases is provided in the Supplement (Table S3).

\subsection{QSAR prediction of in vitro genotoxicity}

The 104 aerosol compounds were then screened for their mutagenic potential by means of QSAR predictions. QSAR predictions for Salmonella in vitro mutagenicity (Ames test) were generated by employing two models: (i) the ACD impurity profiling model for Salmonella composite implemented in the commercial software ACD/Labs Percepta (ACD/Percepta, release 2015, www.acdlabs.com) and (ii) the VEGA CAESAR mutagenicity model implemented in the open platform VegaNIC (VegaNIC Application ver. 1.1.0, https://www.vegahub.eu/portfolio-item/vega-qsar/, last access: February 2018). The two models, which fulfil the OECD principles for QSAR scientific validity, provide qualitative predictions for genotoxicity as an Ames test (e.g. positive or negative) supported with specific parameters providing information on prediction reliability. Detailed information on the employed models are provided in the Supplement (Table S4). The two QSAR models were used in order to complement each other. In the case of conflicting reliable predictions, the most conservative health impact potential, i.e. positive prediction, was assigned.

\subsection{Cluster analysis}

A workflow for clustering the 104 aerosol compounds was designed with the aim of grouping compounds into clusters sharing similar physico-chemical, structural, and mechanistic profiles (Fig. S1). The workflow was automatized using the KNIME Analytics Platform (Berthold et al., 2007) and is described below.

Step 1 Calculate descriptors accounting for physico-chemical, molecular, and reactivity properties, such as LogP (log octanol-water partition coefficient), WS (water solubility), MW (molecular weight), TPSA (total polar surface area), nHBDon (number of donor atoms for hydrogen bonds), nHBAcc (number of acceptor atoms for hydrogen bonds), HOMO (highest occupied molecular orbital), and LUMO (lowest unoccupied molecular orbital). These were calculated using PaDEL-Descriptors (Yap et al., 2011), ACD/Percepta, and Schrödinger software (Schrödinger Suite 2014 Update 3 Release, Maestro v9.9.013; September 2014, evaluation copy). Bidimensional molecular descriptors (e.g. constitutional, topological, shape descriptors) were also calculated using PaDEL-Descriptors. Descriptors providing mechanistic information for genotoxic activity were derived using five genotoxicity profilers implemented in the OECD QSAR Toolbox (Table S2). In particular, the employed profilers identify in the target chemicals the presence of structural alerts for DNA binding or mutagenicity, with or without the associated MoA (mechanism of action) responsible for genotoxic activity. The outcome of the profilers was used to derive the mechanistic descriptors, which consisted of binary variables indicating the presence (1) or absence (0) of a structural alert (with or without MoA information). A total of $138 \mathrm{de}-$ scriptors, including 18 physico-chemical descriptors, 70 structural descriptors, and 50 mechanistic descriptors, were calculated. The complete list of calculated descriptors and their description is provided in the Supplement (Table S5).

Step 2 To reduce redundant and non-useful information, constant descriptors (i.e. descriptors having the same value for all the compounds) and pair-correlated descriptors (i.e. descriptors with pairwise correlation $>0.8$ ) among the physico-chemical and structural descriptors were removed. The initial set of 138 descriptors was reduced to 75 variables, including all 50 mechanistic descriptors, 8 PC descriptors, and 17 structural descriptors (Table S5). Mechanistic descriptors were binary variables $(0,1)$, while physico-chemical and structural descriptors were continuous variables. Thus, to analyse the three groups of descriptors in combination, continuous variables (i.e. physico-chemical and structural descriptors) were normalized within the $0-1$ range. 
Table 1. Experimental data for Salmonella in vitro mutagenicity.

\begin{tabular}{llll}
\hline Compound name & No. of studies & Test calls & Overall outcome $^{\mathrm{c}}$ \\
\hline 2-nitrophenol & $23^{\mathrm{a} ; \mathrm{b}}$ & $-(23)$ & - \\
2-methylphenol & $20^{\mathrm{a} ; \mathrm{b}}$ & $-(20)$ & - \\
naphthol & $11^{\mathrm{a} ; \mathrm{b}}$ & $-(9),+(2)$ & + \\
naphthoquinone & $17^{\mathrm{a} ; \mathrm{b}}$ & $-(13),+(3)$, equivocal (1) & + \\
dihydroxy-phthalic acid & $27^{\mathrm{a} ; \mathrm{b}}$ & $-(27)$ & - \\
phenanthrene-9,10-dione & $6^{\mathrm{a} ; \mathrm{b}}$ & $-(6)$ & inconclusive \\
phenanthren-9-ol & $3^{\mathrm{a} ; \mathrm{b}}$ & $-(1),+(2)$ & + \\
9-nitrophenanthrene & $16^{\mathrm{a} ; \mathrm{b}}$ & $-(2),+(14)$ & + \\
4-nitro-6H-dibenzo[b,d]pyran-6-one & $6^{\mathrm{a} ; \mathrm{b}}$ & $-(5),+(1)$ & + \\
1-nitro-pyrene & $25^{\mathrm{a} ; \mathrm{b}}$ & $-(1),+(19)$, equivocal (3) & + \\
N'-nitrosonornicotine & $18^{\mathrm{a} ; \mathrm{b}}$ & $-(13),+(4)$, equivocal $(1)$ & + \\
4-(methylnitrosoamino)-1-(3-pyridyl)-1-butanone & $7^{\mathrm{a} ; \mathrm{b}}$ & $-(3),+(3)$, equivocal $(1)$ & + \\
4-(methylnitrosoamino)-1-(3-pyridyl)-1-butanol & $1^{\mathrm{a}}$ & + & + \\
\hline
\end{tabular}

${ }^{a}$ Bacterial mutagenicity ISSSTY; ${ }^{b}$ genotoxicity OASIS; ${ }^{c}$ overall outcome according to bacterial mutagenicity ISSSTY assessment: positive ("+"; at least one strain is positive, with or without metabolic activation); "equivocal" (no strain is positive, and at least one equivocal result is present in one of the following strains, with or without metabolic activation: TA1535, TA100, TA98, TA1538, TA1535, TA97); negative ("-_; no positive or equivocal results are present in any strain, and negative outcomes exist for (a) at least one strain from among TA1535, TA100, or TA97, with and without metabolic activation, and (b) at least one strain from among TA1538, TA98, or TA1537, with and without metabolic activation); "inconclusive" (if none of the above criteria are fulfilled). Full information on genotoxicity observation data (strains, metabolic activation, etc.) with references can be found in Table S6.

Step 3 A principal component analysis (PCA) was performed on the final set of 75 descriptors to extract important information encoded by physico-chemical, structural, and mechanistic properties and to reduce the number of input variables used for cluster analysis. The PCA was carried out in KNIME by employing specific nodes for PCA (i.e. PCA compute and PCA apply) based on the covariance matrix implementation method. The first 13 principal components (PCs) of the PCA were maintained, which preserved $85 \%$ of the information encoded in the original variables.

Step 4 Hierarchical clustering of the 104 compounds was performed using as input variables the first 13 principal components (PCs) of the PCA (see Step 3). An agglomerative clustering was performed by employing the hierarchical clustering KNIME node (metric: Euclidean distance; linkage criterion: average linkage). The number of clusters was set a priori $(n=10)$.

\section{Results}

\subsection{Screening for genotoxicity - experimental data}

Experimental data for Salmonella in vitro mutagenicity (Ames test) were available for 13 out of 104 aerosol compounds (i.e. $\approx 13 \%$ ). These compounds include aromatic oxygenated compounds (found among the PAH-SOA constituents) and $\mathrm{N}$-nitrosamines (formed by amine oxidation and NO addition). A summary of retrieved data is provided in Table 1. Detailed information on the retrieved experimental data is reported in the Supplement (Table S6). Overall, it was noted that consistent negative experimental Ames test data (conducted on different Salmonella strains, with and without metabolic activation) are available for four compounds (two substituted benzene SOA compounds and two from PAH-SOA). In addition, consistent positive experimental Ames test data (different Salmonella strains, with and without metabolic activation) are available for two compounds (one PAH-SOA compound and one amine SOA), while for the remaining seven compounds, both positive and negative Ames test results are reported based on the Salmonella strain and testing conditions used.

\subsection{Screening for genotoxicity - QSAR-predicted data}

In silico predictions for Salmonella in vitro mutagenicity were generated for the 104 studied aerosols by employing two QSAR models, i.e. the ACD/Percepta impurity (Salmonella composite) model and the VEGA CAESAR mutagenicity model. Predictions obtained by the two QSARs were combined taking into account the applicability domain of each model and consistency among predictions (Table S7). Predictions were assessed for their reliability and different levels of confidence were assigned ("not", "borderline", "moderate", and "high" reliable predictions). Overall, the predictions generated by the two QSAR models were in agreement for the majority of compounds (inconsistent predictions obtained for only 4 compounds out of the 53 reliably predicted by both QSAR models) and the combination of the two tools resulted in successfully covering a wider chemical space $(59 \%$ of compounds reliably predicted by ACD/Percepta alone, $74 \%$ of compounds reliably predicted by VEGA CAESAR alone, $82 \%$ of compounds re- 

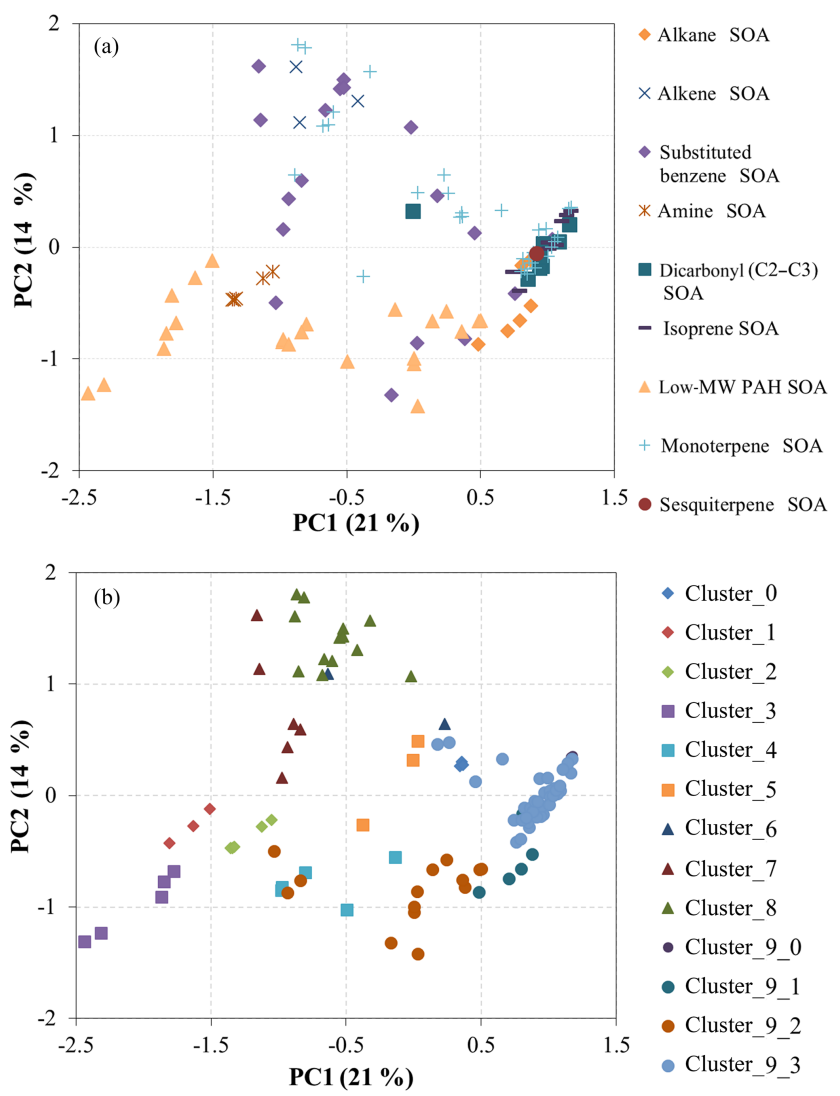

Figure 1. PCA score plot of 104 aerosol compounds: compounds marked according to different SOA classes (a) and compounds marked according to different clusters (b).

liably predicted by combining the two QSAR models). As far as the four compounds with opposite predictions are concerned, this is mainly due to issues related to the different applicability domain of the two QSAR models. Based on the combined predictions, 53 compounds were predicted as negative, 32 as positive (including four compounds with conflicting reliable predictions), and 19 compounds QSAR predictions were assessed as "indeterminate" (i.e. not reliable or equivocal predictions; Table 2).

It is worth noting that $30 \%$ of the compounds were screened as genotoxic by at least one of the two QSAR models employed in this study. These genotoxic SOA components included all five $\mathrm{N}$-nitrosamines from amine atmospheric oxidation, but none of the compounds chosen to represent isoprene SOA, sesquiterpene SOA, or (among the anthropogenic) alkane photo-oxidation SOA. On the other hand, the relatively large classes of compounds in the list correspondent to monoterpene SOA, substituted benzene SOA, and PAH-SOA included both several genotoxic and nongenotoxic species. In the following section, we provide clues for understanding inter- and intra-class variability.
Table 2. Results of the QSAR genotoxicity predictions from VEGA CAESAR and ACD/Percepta models.

\begin{tabular}{|c|c|c|c|c|c|c|}
\hline & \multicolumn{5}{|c|}{ VEGA CAESAR } \\
\hline & & Negative & Positive & out & $\mathrm{n} / \mathrm{a}$ & tot \\
\hline \multirow{5}{*}{ 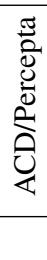 } & Negative & 36 & 3 & 7 & - & 46 \\
\hline & Positive & 1 & 13 & - & 1 & 15 \\
\hline & Equivocal & - & 2 & 4 & - & 6 \\
\hline & out & 10 & 12 & 14 & 1 & 37 \\
\hline & tot & 47 & 30 & 25 & 2 & 104 \\
\hline
\end{tabular}

By combining predictions obtained by the two models, the total number of compounds classified as genotoxic from either VEGA CAESAR or

ACD/Percepta amounts to 32 species (bold italic); the number of compounds determined as non-genotoxic by one model and that is not classified as genotoxic by the other is 53 (italic); the number of compounds classified as indeterminate (i.e. "equivocal" or "not reliable" prediction; bold) by both methods is 19 .

\subsection{Cluster analysis}

The goal of cluster analysis is twofold: (1) to identify genotoxicity trends within clusters and (2) to identify gaps in experimental and in silico genotoxicity data. Hierarchical clustering initially resulted in 10 clusters, each characterized by a different composition in terms of the number of compounds belonging to each cluster and the SOA class of each compound. Due to the high number of the members included in Cluster 9, an additional hierarchical clustering was performed on this cluster, which leads to four sub-clusters which are reported as such in the proceeding analysis. Therefore, a total of 13 clusters were generated, as illustrated in Table S9. The 104 compounds are also visualized in the PCA score plots (Fig. 1), in which compounds are displayed in the space described by the first two principal components (PCs) and marked with different colours based on SOA classes and on clusters. The corresponding loading plot can be found in Fig. S2.

The figure shows that SOA classes with compounds located in confined regions of the PCA score plots often correspond to individual clusters (e.g. amine SOA with Cluster 2), while monoterpene SOA, substituted benzene SOA, and PAH-SOA intercept more clusters and show diverse behaviours in the space described by the first two PCs. The distribution of compounds in the score plots of the first two PCs, which explain $35 \%$ of the total variance, is primarily based on the mechanistic descriptors. In particular, compounds with no or few structural alerts for genotoxicity (e.g. compounds belonging to Cluster 9) are displayed in the bottom-right part of the plots (Fig. S2), while the remaining compounds exhibit different alerts and mechanisms for genotoxicity. In particular, typical descriptors for the clusters characterized by high values of the second PC (Clusters 7 and 8) are radical reactivity via ROS formation and the occurrence of hydroxyperoxides and $\mathrm{H}$-acceptor-path3-H-acceptor 
substructures (two hydrogen acceptors at a distance of three atoms; Fig. S2). The role of other relevant descriptors (e.g. lipophilicity, electronic descriptors, etc.) in the distribution of compounds among different clusters becomes more evident when analysing the other principal components.

Within each cluster, SOA compounds were analysed in terms of structural and physico-chemical properties, mechanistic profile, and mutagenic potential. The analysis and results for each cluster are provided in the Supplement (Table S8a, b) but we present the overarching results in the following. In general, SOA classes (defined by the nature of precursors) show a variable degree of overlap with the clusters: there are some well-populated clusters that include multiple SOA classes, in particular Sub-cluster 9-3, including many aliphatic compounds from isoprene, dicarbonyls, monoterpene, and substituted benzene oxidation, and which are mostly non mutagenic. On the other hand, there are distinct clusters of mutagenic or non-mutagenic compounds that are associated with specific SOA systems (Fig. 2; e.g. Cluster 1: mutagenic quinones from PAH oxidation, and Subcluster 9-1: alkane SOA, all non-mutagenic). By combining the information on compounds and properties from the clusters (encoding physico-chemical, structural, and mechanistic descriptors of the compounds) with that of sources (specific SOA systems; Table S9), we can list the following groups of mutagenic compounds (with characteristics of their mechanistic profile provided in parentheses).

- Cluster 0 contains five-membered-lactones in monoterpene SOA (alkylation via the Michael-type addition of five-membered-lactone and via ring opening SN2 reaction).

- Cluster 1 contains quinones from low-MW PAH oxidation (DNA intercalation, radical reaction mechanism via ROS formation, Michael addition to quinoid structure).

- Cluster 2 contains N-nitrosamines (nucleophilic attack after nitrenium or carbenium ion formation).

- Cluster 3 contains hydroxy- and nitro-PAHs (several mechanisms, including DNA intercalation, ROS formation, and nucleophilic attack after reduction and nitrenium ion formation). The same cluster includes one glyoxal-imidazole, for which no reliable QSAR prediction was obtained. For this compound experimental testing for mutagenicity is recommended.

- Cluster 7 contains non-aromatic products of substituted benzene oxidation (several mechanisms including ROS formation, alkylation by epoxides, and reactions involving an $\mathrm{H}$-acceptor-path3-H-acceptor). This cluster also includes a formaldehyde-CI adduct formed by monoterpene ozonolysis.

- Cluster 8 (only 5 out of 13 mutagenic) contains alkyl hydroperoxides and peroxyacids from substituted ben-

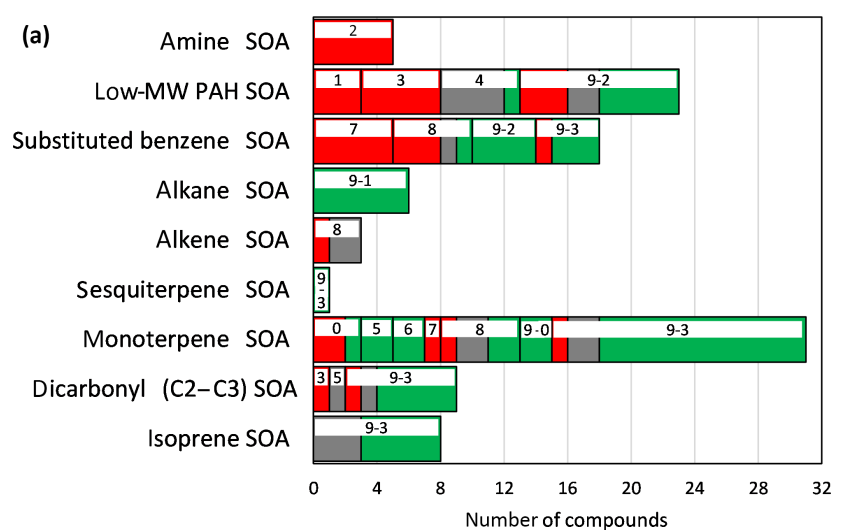

(b)

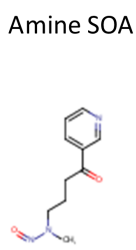

(Cluster 2)

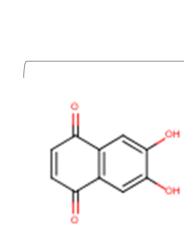

(Cluster 1)
LOW-MW PAH SOA

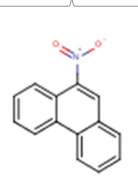

(Cluster 3)

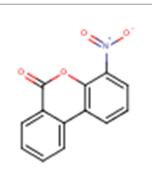

(Cluster 9-2)

Substituted benzene SOA

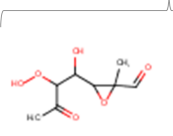

(Cluster 7)

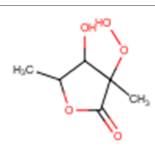

(Cluster 8)
Monoterpene SOA

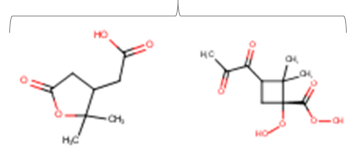

(Cluster 0)

(Cluster 8)

Figure 2. (a) Distribution of mutagenic (red), non-mutagenic (green) and indeterminate (grey) compounds between clusters (labels in white boxes) and SOA classes. (b) Examples of the molecular structures of compounds predicted to be mutagenic.

zene, alkene, and monoterpene oxidation (ROS generation, $\mathrm{H}$-acceptor-path3-H-acceptor reactions) and one five-membered-lactone in substituted benzene SOA (alkylation via the Michael-type addition of fivemembered-lactone).

Other classes of mutagenic compounds were found within Sub-cluster 9-2 (nitro- and oxo-PAHs) and Sub-cluster 9-3 (only three compounds with heterogeneous descriptors). The abundance of mutagenic species in each cluster is graphically represented in Fig. 2 together with examples of the molecular structures of representative mutagenic compounds in each of the major clusters and SOA types.

Note that not all compounds carrying genotoxicity alerts were predicted to be genotoxic by the QSARs. For instance, monoterpene SOA dimers bearing ozonide bonds (Cluster 6) are likely precursors of ROS, but were predicted to be nongenotoxic with a moderate to high reliability. It is worth mentioning that the mechanistic profile (e.g. the presence of reactive functional groups in a molecule) must be considered a collection of alerts and that the mutagenicity depends on all 
the characteristics of the specific compound which affect and modulate the actual expression of the alerts.

The six clusters of compounds listed above, accounting for 26 of the 32 compounds predicted as mutagenic by the QSAR analysis, include three clusters representing groups of compounds with well-known toxicological properties: Nnitrosamines (Cluster 2), hydroxy- and nitro-PAHs (Cluster 3 ), and quinones (Cluster 1). These clusters encompass organic compounds with clear source fingerprints (from PAHs and amine oxidation and reaction with $\mathrm{NO}_{x}$ ) and that are found in polluted environments in concentrations ranging from $10^{-3}$ to $10^{0} \mathrm{ng} \mathrm{m}^{-3}$ (Chung et al., 2006; Huang et al., 2014; Farren et al., 2015; Table S10). Nitro- and oxoaromatic compounds are by far the best-studied mutagenic components of SOA (e.g. Enya et al., 1997; Di Filippo et al., 2007; Huang et al., 2014). They can form upon the oxidation of primary organic compounds which can be also mutagenic (PAHs) or that are just non-toxic, such as methoxy-phenols in biomass burning emissions (Kroflič et al., 2015).

The other three clusters encompass oxygenated organic compounds that, to our knowledge, have been ignored so far in mutagenicity studies of atmospheric aerosol compounds. They could contribute to explaining the yet unknown composition of the most polar fraction of mutagenic compounds in atmospheric aerosol (Barale et al., 1994; Gutiérrez-Castillo et al., 2006; Palacio et al., 2016). First, five-membered lactones formed by the oxidation of monoterpenes are alkylating agents and possibly mutagenic (Cluster 0 ). These include terpenyllic acid, which occurs in concentrations of 6 to $15 \mathrm{ng} \mathrm{m}^{-3}$ in polluted rural areas (Kristensen et al., 2013; Brüggemann et al., 2017). A second class (Cluster 7) of mutagenic compounds encompasses multi-functional oxygenated non-aromatic species (including epoxides) formed from the oxidation of substituted benzenes and the products of the addition of formaldehyde to monoterpene Criegee intermediates. Finally, a more heterogeneous class of SOA compounds originating from both biogenic (monoterpenes) and anthropogenic VOCs (substituted benzenes, alkenes) characterized by the presence of certain functionalities, like hydroperoxy-, peroxy-acidic groups or H-acceptor-path3acceptor structures, account for mutagenic compounds in Cluster 8. No experimental data are available for the ambient concentrations of organic compounds belonging to Clusters 7 or 8 . However, SOA modelling studies indicate that they can account for a significant fraction of SOA mass formed by substituted benzene oxidation (Ruggeri et al., 2016), which translates into ambient concentrations of several $\mathrm{ng} \mathrm{m}^{-3}$ in very polluted environments (such as in Yuan et al., 2013; Table S10). The formation of endoperoxides and epoxides and of other reactive oxygenated organic compounds, such as those in Clusters 7 and 8, was hypothesized by $\mathrm{Fu}$ et al. (2012) to explain the DNA damage caused by photodegraded aromatic compounds. Moreover, the finding of biogenic SOA components with potential mutagenic properties (Cluster 0 and some compounds in Clusters 7 and 8) is in agreement with the results of Alves et al. (2016), showing that the mutagenicity of the aerosol is enhanced when pollution is mixed with emissions in rural areas. The overall picture, however, is that a greater proportion of mutagenic compounds was predicted to occur in the anthropogenic SOA classes than in the biogenic ones (Fig. 2). Exceptions are alkane SOA, which was predicted to be non-mutagenic, and some of the monoterpene SOA, which instead showed mutagenic activity on the basis of our QSAR approach. These results show a very good qualitative overlap with the findings of Verma et al. (2015) and Tuet et al. (2017) about the redox potentials of specific classes of SOA. Although ROS expression is only one of the possible mechanisms of action responsible for mutagenicity, it characterizes several of the compounds predicted to be mutagenic in our study, especially in Clusters 1, 3, 7, and 8. The formation of ROS in atmospheric SOA and the genotoxic effect of oxidative stress caused by PM exposure have been documented by a number of studies (e.g. Risom et al., 2005; Valavanidis et al., 2008; Rattanavaraha et al., 2011; Oh et al., 2011; Fu et al., 2012).

As a final remark, it should be noted that the vast sets of molecular structures emerging from laboratory experiments on the best-studied SOA systems (such as monoterpene and substituted benzene SOA) include compounds of very diverse chemical and biological activity. As a corollary, it is possible that expanding the chemical characterization of the SOA components from other VOC precursors will lead to the identification of new potential mutagens. In summary, the identification of new classes of compounds with predicted mutagenic activity calls for more research on the identification and quantification of such compounds in ambient aerosol samples, as well as on the toxicological properties of the specific SOA systems, and for precautions in laboratories involved in the synthesis of SOA tracer compounds (Nozière et al., 2015).

\section{Conclusions}

The present study represents a hitherto unexplored proofof-concept investigation indicating that in silico methods might be successfully employed to support the safety assessment of atmospheric aerosol organic compounds through the screening and prioritization of the most hazardous ones based solely on the information of the chemical structure. In addition, the clustering of chemicals into small groups sharing common structural features, physico-chemical properties, and mechanistic profiles sets the basis for the application of the read-across approach, in which a few representative compounds are tested and the outcome is extrapolated to similar compounds. The results, based on a list of $\sim 100$ individual organic compounds representative of the most important anthropogenic and biogenic SOA classes, indicate that diverse groupings of molecular species exerting specific genotoxic effects might be of importance, and among these are 
classes of SOA compounds previously unexplored for their mutagenic potential. These include five-membered lactones and a heterogeneous class of oxygenated compounds with epoxide and peroxide functionalities and promoting ROS expression. Since, in our list of 104 compounds, redox-active species with mutagenic properties are more frequently found in SOA formed by the degradation of aromatic VOCs, the apportionment of genotoxic compounds among SOA classes shows an overall dominance of anthropogenic over biogenic species (Fig. 2). Therefore these results, based on a first application of in silico methods on a limited number of molecular species, are in qualitative agreement with the existing general knowledge of aerosol health effects indicating a more robust association of combustion-generated aerosols with adverse outcomes with respect to other aerosol sources (Delfino et al., 2009).

The usefulness of in silico methods is their ability to screen vast sets of aerosol organic substances. In principle this would include a much larger set than the 104 compounds considered here, whilst at the same time providing directions for implementing targeted in vitro (and in vivo) toxicological assessments on specific compounds. As already noted, there have been significant advances in atmospheric aerosol modelling and instrumentation. We cannot measure every compound in atmospheric aerosol. As mechanistic models have the potential to predict concentrations of many millions of compounds (McVat et al., 2016), even with uncertain process descriptions, the challenge is how to use this growing amount of information in a meaningful way. As we continually identify and hypothesize new processes and compounds deemed important for better understanding aerosol transformation and impacts, employing automated in silico methodologies offers us the opportunity to replicate this proof-ofconcept study with many simulations of a changing environment.

Data availability. All data, including the detailed results of the QSAR predictions and of cluster analysis, are compiled in the tables accessible in the Supplement.

\section{The Supplement related to this article is available online at https://doi.org/10.5194/acp-18-2329-2018-supplement.}

Competing interests. The authors declare that they have no conflict of interest.

Acknowledgements. This study was partly funded by the National Environment Research Council in the UK (NERC) during project NE/J02175X/1.
Edited by: Athanasios Nenes

Reviewed by: two anonymous referees

\section{References}

Alves, D. K. M., Kummrow, F., Cardoso, A. A., Morales, D. A., and Umbuzeiro, G. A.: Mutagenicity Profile of Atmospheric Particulate Matter in a Small Urban Center Subjected to Airborne Emission From Vehicle Traffic and Sugar Cane Burning, Environ. Mol. Mutagen., 57, 41-50, 2016.

Atkinson, R. W., Fuller, G. W., Anderson, H. R., Harrison, R. M., and Armstrong, B.: Urban ambient particle metrics and health: a time-series analysis, Epidemiology, 21, 501-511, 2010.

Barale, R., Giromini, L., Del Ry, S., Barnini, B., Bulleri, M., Barrai, I., Valerio, F., Pala, M., and He, J.: Chemical and Mutagenic Patterns of Airborne Particulate Matter Collected in 17 Italian Towns, Environ. Health Perspect., 102, 67-73, 1994.

Beelen, R., Raaschou-Nielsen, O., Stafoggia, M., Andersen, Z. J., Weinmayr, G., Hoffmann, B., Wolf, K., Samoli, E., Fischer, P., Nieuwenhuijsen, M., Vineis, P., Xun, W. W., Katsouyanni, K., Dimakopoulou, K., Oudin, A., Forsberg, B., Modig, L., Havulinna, A. S., Lanki, T., Turunen, A., Oftedal, B., Nystad, W., Nafstad, P., De Faire, U., Pedersen, N. L., Östenson, C. G., Fratiglioni, L., Penell, J., Korek, M., Pershagen, G., Eriksen, K. T., Overvad, K., Ellermann, T., Eeftens, M., Peeters, P. H., Meliefste, K., Wang, M., Bueno-de-Mesquita, B., Sugiri, D., Krämer, U., Heinrich, J., de Hoogh, K., Key, T., Peters, A., Hampel, R., Concin, H., Nagel, G., Ineichen, A., Schaffner, E., ProbstHensch, N., Künzli, N., Schindler, C., Schikowski, T., Adam, M., Phuleria, H., Vilier, A., Clavel-Chapelon, F., Declercq, C., Grioni, S., Krogh, V., Tsai, M. Y., Ricceri, F., Sacerdote, C., Galassi, C., Migliore, E., Ranzi, A., Cesaroni, G., Badaloni, C., Forastiere, F., Tamayo, I., Amiano, P., Dorronsoro, M., Katsoulis, M., Trichopoulou, A., Brunekreef, B., and Hoek, G.: Effects of long-term exposure to air pollution on natural-cause mortality: an analysis of 22 European cohorts within the multicentre ESCAPE project, Lancet, 383, 785-795, 2014.

Benfenati, E.: In Silico Methods for Predicting Drug Toxicity, in: Methods in Molecular Biology, Vol 1425, Humana press Springer Science+Business Media: New York, 2016.

Berthold, M. R., Cebron, N., Dill, F., Gabriel, T. R., Kötter, T., Meinl, T., Ohl, P., Sieb, C., Thiel, K., and Wiswedel, B.: KNIME: The Konstanz Information Miner, in: Studies in Classification, Data Analysis, and Knowledge Organization (GfKL 2007), Springer, 2007.

Brüggemann, M., Poulain, L., Held, A., Stelzer, T., Zuth, C., Richters, S., Mutzel, A., van Pinxteren, D., Iinuma, Y., Katkevica, S., Rabe, R., Herrmann, H., and Hoffmann, T.: Realtime detection of highly oxidized organosulfates and BSOA marker compounds during the F-BEACh 2014 field study, Atmos. Chem. Phys., 17, 1453-1469, https://doi.org/10.5194/acp17-1453-2017, 2017.

Cassee, F. R., Héroux, M-.E., Gerlofs-Nijland, M. E., and Kelly, F. J.: Particulate matter beyond mass: recent health evidence on the role of fractions, chemical constituents and sources of emission, Inhal Toxicol., 25, 802-812, 2013.

Cassoni, F., Bocchi, C., Martino, A., Pinto, G., Fontana, F., and Buschini, A.: The Salmonella mutagenicity of urban airborne par- 
ticulate matter $\left(\mathrm{PM}_{2.5}\right)$ from eight sites of the Emilia-Romagna regional monitoring network (Italy), Sci. Total Environ., 324, 7990, 2004.

Chen, X., Hopke, P. K., and Carter, W. P. L.: Secondary organic aerosol from ozonolysis of biogenic volatile organic compounds: chamber studies of particle and reactive oxygen species formation, Environ. Sci. Technol., 45, 276-282, 2011.

Chung, M. Y., Lazaro, R. A., Lim, D., Jackson, J., Lyon, J., Rendulic, D., and Hasson, A. S.: Aerosol-borne quinones and reactive oxygen species generation by particulate matter extracts, Environ. Sci. Technol., 40, 4880-4886, 2006.

Delfino, R. J., Staimer, N., Tjoa, T., Polidori, A., Arhami, M., Gillen, D. L., Kleinman, M. T., Vaziri, N. D., Longhurst, J., Zaldivar, F., and Sioutas, C.: Circulating biomarkers of inflammation, antioxidant activity, and platelet activation are associated with urban air pollution in elderly subjects with a history of coronary artery disease, Environ. Health Perspect., 116, 898906, 2008

Delfino, R. J., Staimer, N., Tjoa, T., Gillen, D. L., Polidori, A., Arhami, M., Kleinman, M. T., Vaziri, N. D., Longhurst, J., and Sioutas, C.: Air Pollution Exposures and Circulating Biomarkers of Effect in a Susceptible Population: Clues to Potential Causal Component Mixtures and Mechanisms, Environ. Health. Perspect., 117, 152-156, 2009.

Di Filippo, P., Riccardi, C., Gariazzo, C., Incoronato, F., Pomata, D., Spicaglia, S., and Cecinato, A.: Air pollutants and the characterization of the organic content of aerosol particles in a mixed industrial/semi-rural area in central Italy, J. Environ. Monit., 9, 275-282, 2007.

ECHA - European Chemicals Agency: Practical Guide 5: How to use and report (Q)SARs. ECHA-16-B-09-EN. DOI 10.2823/81818, available at: https://echa.europa.eu/documents/ 10162/13655/pg_report_qsars_en.pdf (last access: February 2018), 2016.

Enya, T., Suzuki, H., Watanabe, T., Hirayama, T., and Hisamatsu, Y.: 3-Nitrobenzanthrone, a Powerful Bacterial Mutagen and Suspected Human Carcinogen Found in Diesel Exhaust and Airborne Particulates, Environ. Sci. Technol., 31, 2772-2776, 1997.

Farren, N. J., Ramirez, N., Lee, J. D., Finessi, E., Lewis, A. C., and Hamilton, J. F.: Estimated exposure risks from carcinogenic nitrosamines in urban airborne particulate matter, Environ. Sci. Technol., 49, 9648-9656, 2015.

Filep, A., Drinovec, L., Palagyi, A., Manczinger, L., Vagvolgyi, C., Bozoki, Z., Hitzenberger, R., and Szabo, G.: Source Specific Cyto- and Genotoxicity of Atmospheric Aerosol Samples, Aerosol Air Qual. Res., 15, 2325-2331, 2015.

Fu, P. P., Xia, Q., Sun, X., and Yu, H.: Phototoxicity and Environmental Transformation of Polycyclic Aromatic Hydrocarbons (PAHs) - Light-Induced Reactive Oxygen Species, Lipid Peroxidation, and DNA Damage, J. Environ. Sci. Health C, 30, 1-41, 2012.

Gutiérrez-Castillo, M. E., Roubicek, D. A., Cebrian-Garcia, M. E., De Vizcaya-Ruiz, A., Sordo-Cedeno, M., and OstroskyWegman, P.: Effect of Chemical Composition on the Induction of DNA Damage by Urban Airborne Particulate Matter, Environ. Mol. Mutagen., 47, 199-211, 2006.

Hallquist, M., Wenger, J. C., Baltensperger, U., Rudich, Y., Simpson, D., Claeys, M., Dommen, J., Donahue, N. M., George, C., Goldstein, A. H., Hamilton, J. F., Herrmann, H., Hoff- mann, T., Iinuma, Y., Jang, M., Jenkin, M. E., Jimenez, J. L., Kiendler-Scharr, A., Maenhaut, W., McFiggans, G., Mentel, Th. F., Monod, A., Prévôt, A. S. H., Seinfeld, J. H., Surratt, J. D., Szmigielski, R., and Wildt, J.: The formation, properties and impact of secondary organic aerosol: current and emerging issues, Atmos. Chem. Phys., 9, 5155-5236, https://doi.org/10.5194/acp9-5155-2009, 2009.

Hannigan, M. P., Rusby Jr., W. F., and Cass, G. R.: Source Contributions to the Mutagenicity of Urban Particulate Air Pollution, J. Air Waste Manage. Assoc., 55, 399-410, 2005.

HEI: Panel on the Health Effects of Traffic-Related Air Pollution, Traffic-related air pollution: a critical review of the literature on emissions, exposure, and health effects. Boston: Health Effects Institute, Special Report 17, 2010.

Huang, B., Liu, M., Bi, X., Chaemfa, C., Ren, Z., Wang, X., Sheng, G., and Fu, J.: Phase distribution, sources and risk assessment of PAHs, NPAHs and OPAHs in a rural site of Pearl River Delta region, China, Atmos. Poll. Res., 5, 210-218, 2014.

Janssen, N. A., Hoek, G., Simic-Lawson, M., Fischer, P., van Bree, L., ten Brink, H., Keuken, M., Atkinson, R. W., Anderson, H R., Brunekreef, B., and Cassee, F. R.: Black carbon as an additional indicator of the adverse health effects of airborne particles compared with $\mathrm{PM}_{10}$ and $\mathrm{PM}_{2.5}$, Environ. Health Perspect., 119, 1691-1699, 2011.

Kamens, R. M., Rives, G. D., Perry, J. M., Bell, D. A., Paylor Jr. R. F., Goodmanm, R. G., and Claxton, L. D.: Mutagenic changes in dilute wood smoke as it ages and reacts with ozone and nitrogen dioxide: an outdoor chamber study, Environ. Sci. Technol., 18, 523-530, 1984.

Kristensen, K., Enggrob, K. L., King, S. M., Worton, D. R., Platt, S. M., Mortensen, R., Rosenoern, T., Surratt, J. D., Bilde, M., Goldstein, A. H., and Glasius, M.: Formation and occurrence of dimer esters of pinene oxidation products in atmospheric aerosols, Atmos. Chem. Phys., 13, 3763-3776, https://doi.org/10.5194/acp13-3763-2013, 2013.

Kristensen, K., Cui, T., Zhang, H., Gold, A., Glasius, M., and Surratt, J. D.: Dimers in $\alpha$-pinene secondary organic aerosol: effect of hydroxyl radical, ozone, relative humidity and aerosol acidity, Atmos. Chem. Phys., 14, 4201-4218, https://doi.org/10.5194/acp-14-4201-2014, 2014.

Kroflic, A., Grilc, M., and Grgic, I.: Does toxicity of aromatic pollutants increase under remote atmospheric conditions?, Scientific Reports 5, Article number: 8859, 2015.

Künzi, L., Krapf, M., Daher, N., Dommen, J., Jeannet, N., Schneider, S., Platt, S., Slowik, J. G., Baumlin, N., Salathe, M., Prévôt, A. S. H., Kalberer, M., Strähl, C., Dümbgen, L., Sioutas, C., Baltensperger, U., and Geiser, M.: Toxicity of aged gasoline exhaust particles to normal and diseased airway epithelia, Sci. Rep., 5, 11801, 2015.

Lakey, P. S. J., Berkemeier, T., Tong, H., Arangio, A. M., Lucas, K., Pöschl, U., and Shiraiwa, M.: Chemical exposure-response relationship between air pollutants and reactive oxygen species in the human respiratory tract, Sci. Rep., 6, 32916, 2016.

Laskin, A., Nizkorodov, S. A., and Laskin, J.: Mass spectrometric approaches for chemical characterization of atmospheric aerosols: critical review of the most recent advances, Environ. Chem., 9, 163-189, 2012.

Lim, S. S., Vos, T., Flaxman, A. D., et al.: A comparative risk assessment of burden of disease and injury attributable to 67 risk 
factors and risk factor clusters in 21 regions, 1990-2010: a systematic analysis for the Global Burden of Disease Study 2010, Lancet, 380, 2224-2260, 2012.

Lin, Y.-H., Knipping, E. M., Edgerton, E. S., Shaw, S. L., and Surratt, J. D.: Investigating the influences of $\mathrm{SO}_{2}$ and $\mathrm{NH}_{3}$ levels on isoprene-derived secondary organic aerosol formation using conditional sampling approaches, Atmos. Chem. Phys., 13, 84578470, https://doi.org/10.5194/acp-13-8457-2013, 2013.

McVay, R. C., Zhang, X., Aumont, B., Valorso, R., Camredon, M., La, Y. S., Wennberg, P. O., and Seinfeld, J. H.: SOA formation from the photooxidation of $\alpha$-pinene: systematic exploration of the simulation of chamber data, Atmos. Chem. Phys., 16, 27852802, https://doi.org/10.5194/acp-16-2785-2016, 2016.

Netzeva, T. I., Worth, A. P., Aldenberg, T., Benigni, R., Cronin, M. T. D., Gramatica, P., Jaworska, J. S., Kahn, S., Klopman, G., Marchant, C. A., Myatt, G., Nikolova-Jeliazkova, N., Patlewicz, G. Y., Perkins, R., Roberts, D.W., Schultz, T. W., Stanton, D. T., van de Sandt, J. J. M., Tong, W., Veith, G., and Yang, C.: Current status of methods for defining the applicability domain of (quantitative) structure-activity relationships. The report and recommendations of ECVAM Workshop 52. Alternatives to Laboratory Animals (ATLA), 33, 155-173, 2005.

Nozière, B., Kalberer, M., Claeys, M., Allan, J., D’Anna, B., Decesari, S., Finessi, E., Glasius, M., Grgić, I., Hamilton, J. F., Hoffmann, T., Iinuma, Y., Jaoui, M., Kahnt, A., Kampf, C. J., Kourtchev, I., Maenhaut, W., Marsden, N., Saarikoski, S., Schnelle-Kreis, J., Surratt, J. D., Szidat, S., Szmigielski, R., and Wisthaler, A.: The Molecular Identification of Organic Compounds in the Atmosphere: State of the Art and Challenges, Chem. Rev., 115, 3919-3983, 2015.

OECD - Organization for Economic Cooperation and Development: OECD series on testing and assessment. No. 49. The report from the expert group on (Quantitative) Structure-Activity Relationships [(Q)SARs] on the principles for the validation of (Q)SARs. ENV/JM/MONO(2004)24, 2nd Meeting of the ad hoc Expert Group on QSARs, OECD Headquarters, 20-21 September 2004, available at: http: //www.oecd.org/officialdocuments/publicdisplaydocumentpdf/ ?doclanguage $=$ en $\&$ cote $=$ env $/ j m / \operatorname{mono}(2004) 24$ (last access: February 2018), 2004.

OECD - Organization for Economic Co-operation and Development: Report on the Regulatory Uses and Applications in OECD Member Countries of (Quantitative) StructureActivity Relationship [(Q)SAR] Models in the Assessment of New and Existing Chemicals, OECD Environment Health and Safety Publications, Series on Testing and Assessment No. 58. ENV/JM/MONO, 25, available at: http: //www.oecd.org/officialdocuments/publicdisplaydocumentpdf/ ?cote $=$ env $/ \mathrm{jm} / \mathrm{mono}(2006) 25 \&$ doclanguage $=$ en (last access: 11 May 2015), 2006.

OECD - Organization for Economic Co-operation and Development: Guidance document on the Validation of (Quantitative) Structure Activity Relationship [(Q)SAR] Models. OECD Environment Health and Safety Publications, Series on Testing and Assessment No. 69. ENV/JM/MONO, 2007, 2, available at: http: //www.oecd.org/officialdocuments/publicdisplaydocumentpdf/ ?cote $=$ env $/ \mathrm{jm} / \mathrm{mono}(2007) 2 \&$ doclanguage $=$ en (last access: 11 April 2016), 2007.
OECD - Organization for Economic Co-operation and Development: Guidance document for using the OECD (Q)SAR Application Toolbox to develop chemical categories according to the OECD Guidance on Grouping of Chemicals, OECD Environment Health and Safety Publications, Series on Testing and Assessment No. 102. ENV/JM/MONO, 2009, 5, available at: http: //www.oecd.org/officialdocuments/publicdisplaydocumentpdf/ ?doclanguage $=$ en $\&$ cote $=$ env $/ \mathrm{jm} / \mathrm{mono}(2009) 5$ (last access: February 2018), 2009.

OECD - Organization for Economic Co-operation and Development: User Manual based on QSAR Toolbox version 3.0. Strategies for grouping chemicals to fill data gaps to assess genetic toxicity and genotoxic carcinogenicity, available at: http:// www.oecd.org/env/ehs/risk-assessment/genetictoxicity.pdf (last access: February 2018), 2013.

OECD: (Q)SAR Application Toolbox, version 3.3.2 (2015) Organization for Economic Co-operation and Development, available at: http://www.oecd.org/chemicalsafety/risk-assessment/ theoecdqsartoolbox.htm (last access: 6 May 2015), 2015.

Palacio, I. C., Barros, S. B. M., and Roubicek, D. A.: Water-soluble and organic extracts of airborne particulate matter induce micronuclei in human lung epithelial A549 cells, Mutation Research, 812, 1-11, 2016.

Oh, S. M., Kim, H. R., Park, Y. J., Lee, S. Y., and Chung, K. H.: Organic extracts of urban air pollution particulate matter $\left(\mathrm{PM}_{2.5}\right)$-induced genotoxicity and oxidative stress in human lung bronchial epithelial cells (BEAS-2B cells), Mutation Research, 723, 142-151, 2011.

Papa, E., Pilutti, P., and Gramatica, P.: Prediction of PAH mutagenicity in human cells by QSAR classification, SAR QSAR Environ Res., 19, 115-127, 2008.

Pope, C., Brook, R., Burnett, R., and Dockery, D.: How is cardiovascular disease mortality risk affected by duration and intensity of fine particulate matter exposure? An integration of the epidemiologic evidence, Air Qual. Atmos. Health, 4, 5-14, 2011.

Risom, L., Moeller, P., and Loft, S.: Oxidative stress-induced DNA damage by particulate air pollution, Mutation Research, 592, 119-137, 2005.

Rohr, A. C.: The health significance of gas- and particle-phase terpene oxidation products: A review, Environ. Int., 60, 145-162, 2013.

Rattanavaraha, W., Rosen, E., Zhang, H., Li, Q., Pantong, K., and Kamens, R. M.: The reactive oxidant potential of different types of aged atmospheric particles: An outdoor chamber study, Atmos. Environ., 45, 3848-3855, 2011.

Ruggeri, G., Bernhard, F. A., Henderson, B. H., and Takahama, S.: Model-measurement comparison of functional group abundance in $\alpha$-pinene and 1,3,5-trimethylbenzene secondary organic aerosol formation, Atmos. Chem. Phys., 16, 8729-8747, https://doi.org/10.5194/acp-16-8729-2016, 2016.

Saffari, A., Hasheminassab, S., Wang, D., Shafer, M. M., Schauer, J. J., and Sioutas, C.: Impact of primary and secondary organic sources on the oxidative potential of quasi-ultrafine particles (PM0.25) at three contrasting locations in the Los Angeles Basin, Atmos. Environ., 120, 286-296, 2015.

Sahigara, F., Mansouri, K., Ballabio, D., Mauri, A., Consonni, V., and Todeschini, R.: Comparison of Different Approaches to Define the Applicability Domain of QSAR Models, Molecules, 17, 4791-4810, 2012. 
Schultz, T. W., Amcoff, P., Berggren, E., Gautier, F., Klaric, M., Knight, D. J., Mahony, C., Schwarz, M., White, A., and Cronin, M. T. D.: A strategy for structuring and reporting a read-across prediction of toxicity, Regul. Toxicol. Pharm., 72, 586-601, 2015.

Schwarz, M. A., Behnke, A., Brandt, M., Eisenträger, A., Hassauer, M., Kalberlah, F., and Seidel, A.: Semipolar polycyclic aromatic compounds: identification of 15 priority substances and the need for regulatory steps under REACH regulation, Integr Environ Assess Manag., 10, 415-428, 2014.

Stanek, L. W., Sacks, J. D., Dutton, S., and Dubois, J-.J. B.: Attributing health effects to apportioned components and sources of particulate matter: An evaluation of collective results, Atmos. Environ., 45, 5655-5663, 2011.

Sushko, I., Novotarskyi, S., Körner, R., Pandey, A. K., Kovalishyn, V. V., Prokopenko, V. V., and Tetko, I. V.: Applicability domain for in silico models to achieve accuracy of experimental measurements, J. Chemometr., 24, 202-208, 2010.

Tuet, W. Y., Chen, Y., Xu, L., Fok, S., Gao, D., Weber, R. J., and Ng, N. L.: Chemical oxidative potential of secondary organic aerosol (SOA) generated from the photooxidation of biogenic and anthropogenic volatile organic compounds, Atmos. Chem. Phys., 17, 839-853, https://doi.org/10.5194/acp-17-839-2017, 2017.

Valavanidis, A., Fiotakis, K., and Vlachogianni, T.: Airborne Particulate Matter and Human Health: Toxicological Assessment and Importance of Size and Composition of Particles for Oxidative Damage and Carcinogenic Mechanisms, J. Environ. Sci. Health C, 26, 339-362, 2008.

Verma, V., Fang, T., Xu, L., Peltier, R. E., Russell, A. G., Ng, N. L., and Weber, R. J.: Organic Aerosols Associated with the Generation of Reactive Oxygen Species (ROS) by Water-Soluble $\mathrm{PM}_{2.5}$, Environ. Sci. Technol., 49, 4646-4656, 2015.
West, J. J., Cohen, A., Dentener, F, Brunekreef, B., Zhu, T., Armstrong, B., Bell, M. L., Brauer, M., Carmichael, G., Costa, D. L., Dockery, D. W., Kleeman, M., Krzyzanowski, M., Künzli, N., Liousse, C., Lung, S-.C C., Martin, R. V., Pöschl, U., Pope, C. A., Roberts, J. M., Russell, A. G., and Wiedinmyer, C.: What We Breathe Impacts Our Health: Improving Understanding of the Link between Air Pollution and Health, Environ. Sci. Technol., 50, 4895-4904, 2016.

WHO: Review of evidence on health aspects of air pollution REVIHAAP Project, Technical Report, Copenhagen, Denmark: WHO Publications, WHO Regional Office for Europe, 2013.

Worth, A., Fuart-Gatnik, M., Lapenna, S., Lo Piparo, E., MostragSzlichtyng, A., and Serafimova, R.: The Use of Computational Methods in the Toxicological Assessment of Chemicals in Food: Current Status and Future Prospects, JRC Scientific and Technical Reports, EUR 24748 EN. DOI 10.2788/6234, 2011.

Yap, C. W.: PaDEL-Descriptor: An open source software to calculate molecular descriptors and fingerprints, J. Comput. Chem., 32, 1466-1474, 2011.

Yuan, B., Hu, W. W., Shao, M., Wang, M., Chen, W. T., Lu, S. H., Zeng, L. M., and Hu, M.: VOC emissions, evolutions and contributions to SOA formation at a receptor site in eastern China, Atmos. Chem. Phys., 13, 8815-8832, https://doi.org/10.5194/acp13-8815-2013, 2013.

Zhang, Y., Schauer, J. J., Shafer, M. M., Hannigan, M. P., and Dutton, S. J.: Source apportionment of in vitro reactive oxygen species bioassay activity from atmospheric particulate matter, Environ. Sci. Technol., 42, 7502-7509, 2008. 